Portland State University

PDXScholar

\title{
Science in Service of Man: Towards an Understanding of Medicine as an Institution of Control
}

Amanda M. Strother

Portland State University

Follow this and additional works at: https://pdxscholar.library.pdx.edu/honorstheses

Part of the Inequality and Stratification Commons, and the Medicine and Health Commons Let us know how access to this document benefits you.

\section{Recommended Citation}

Strother, Amanda M., "Science in Service of Man: Towards an Understanding of Medicine as an Institution of Control" (2021). University Honors Theses. Paper 1051.

https://doi.org/10.15760/honors.1077

This Thesis is brought to you for free and open access. It has been accepted for inclusion in University Honors Theses by an authorized administrator of PDXScholar. Please contact us if we can make this document more accessible: pdxscholar@pdx.edu. 


\section{Science in Service of Man:}

Towards an Understanding of Medicine as an Institution of Control

by

Amanda Strother

An undergraduate honors thesis submitted in partial fulfillment of the requirements for the degree of

Bachelor of Arts

in

University Honors

and

Sociology

Thesis Adviser

Tina Burdsall

Portland State University 
Table of Contents

ABSTRACT

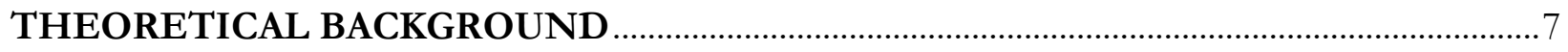

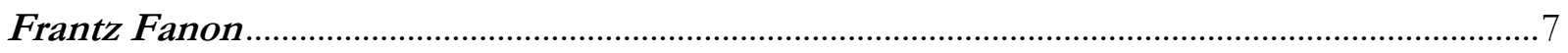

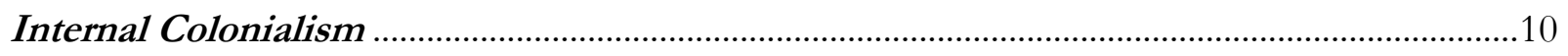

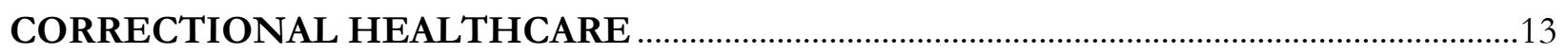

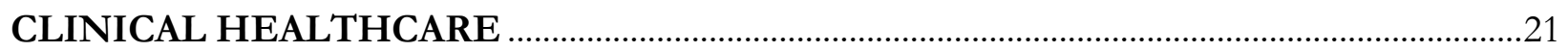

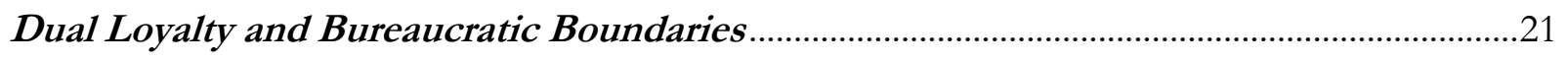

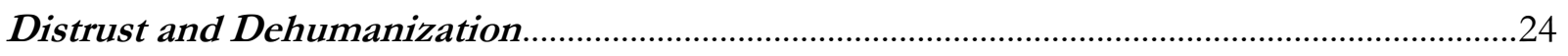

CONCLUSION

REFERENCES 


\begin{abstract}
This paper applies the theoretical work of Frantz Fanon to discuss healthcare as an institution that upholds the will of the dominant authority in the contemporary United States. The use of Fanon's work outside of its original context is justified by applying the internal colonialism theory. Correctional healthcare is discussed as an area of overtly controlling and dehumanizing medical care, highlighting caregiver loyalty to correctional authority and reciprocal distrust between prison physicians and patients. This inquiry proposes that clinical healthcare displays the same power relationships through loyalty to the business of healthcare and the reciprocal distrust between physicians and patients as caregivers strive for an unachievable objectivity of care. Both the correctional and the clinical healthcare sections establish that medicine exists in collaboration with the governing body because: 1) medicine is provided by those in power and they get to determine the boundaries of its provision and, 2) individual caregivers uphold this structure by complying with the dominant interests. Further, both these arenas of study demonstrate that by upholding the will of those in power, interpersonal relations within medical care reproduce the oppressed-oppressor dynamic. This paper advocates for the use of Fanon's work within the contemporary United States contexts and argues that we should understand medical institutions as powerful and socio-politically situated, rather than infallible and absolute.
\end{abstract}

KEYWORDS: medicine, healthcare, Frantz Fanon, internal colonialism, correctional healthcare, clinical healthcare, dual loyalty 
"Science depoliticized, science in service of man, is often non-existent in the colonies."

- Frantz Fanon

A Dying Colonialism 1965, p. 140

\section{INTRODUCTION}

Medical institutions hold enormous power over the health and well-being of those who depend on them for care. As such, it is critical to understand the institution of medicine as socially constructed within a specific political and social context, rather than an unchanging and objective phenomenon. Western conceptions of medicine uphold science as impartial, and this understanding ignores the broader social factors that shape medical knowledge creation and the subjective application of medical care. It is difficult to highlight the motives that have created and bounded medical care in the United States, both presently and historically, because the dominant discourse frames medical oppression in a way that obscures the existence of an oppressor. In this paper, I suggest that understanding the role of medical institutions in colonial contexts allows for a clearer understanding of medicine as a tool of oppression, and I encourage greater scrutiny of how the institution of medicine is used to impose the will of the dominant class in the United States.

This project faces one major challenge: the mechanisms of control and subjugation that the institution of healthcare employs are covert in the United States. The linchpin of the present inquiry is the work of physician and political philosopher Frantz Fanon and his ruminations on the structure of hegemonic colonial oppression in Algeria and how that manifests in medical care. While the works of Fanon that are primarily used in political and historical discourse communities discuss colonial racism and interpersonal colonized-colonizer dynamics more broadly, his book $A$ Dying Colonialism (1965) specifically addresses the colonial situation in Algeria and the context that led to the struggle for Algerian liberation from the occupying French. It is in a chapter of this work, 
entitled "Medicine and Colonialism," that Fanon conceptualizes the role of healthcare in colonial domination, and it is this chapter that will serve as this paper's primary source of Fanon's theory.

The use of Fanon's work throughout this paper will elucidate that medicine is an institution that is controlled by those in power-and is capable of enforcing the will of the dominant authority. It is easier to see the relationship of control within the colonial context because there exists a clear, occupying oppressor that enforces their systems onto the people they colonize. The present analysis will elucidate how U.S. healthcare is likewise used as a tool of the oppressor. I argue that medicine's role in upholding the will of hegemonic authority challenges the presumption that medical care in the contemporary United States is altruistic and impartial. Further, I use Fanon's consideration of the doctor-patient relationship as an enactment of the oppressor-oppressed power relationship to highlight the interpersonal manifestations of the inequitable structure of U.S. healthcare.

Taking Fanon's observations out of their original colonial context is not done lightly; the very specific harm that has occurred via European colonization is not something that should be watered-down nor used for superficial comparison. What I depict within the U.S. institution of medicine will never be a direct comparison to the specific colonial context in Algeria, but the power dynamics at play warrant the application of the process of colonialism. In the second section of this paper, I discuss the theory of internal colonialism. Used by academic theorists and radical activists alike, this theory posits that Black people in America are currently colonized through many of the same tactics as traditional external colonialism: namely social, political, and economic subjugation. Demonstrating that racial relationships in the United States warrant consideration as colonial relationships through similar modes of oppression, I argue that taking Fanon's work outside of its original context is not only justified but critical to our understanding of dominance and deliberate disadvantage. 
In the interest of clarifying this theoretical background, I begin by discussing medical care within correctional healthcare facilities. Prisons serve as my primary area of analysis because they are both geographically and socially removed from larger society, and this isolation allows for a clearer picture of the oppressor-oppressed relationship. Advancing Fanon's understanding of healthcare as a tool of authority, I illustrate that correctional caregivers face conflicting loyalty to both the prison administration and to the needs of their incarcerated patients. Understanding that correctional caregivers primarily serve the interests of the prison fosters a reciprocal distrust between the doctor and the patient. Though this inquiry acknowledges and engages the oppressive dynamics that exist on a relational level, the focus is not on interpersonal bias but rather on clarifying that the relationship between these roles is fundamentally a result of the structure of the institution of medicine.

This paper is heavily inspired by the work of Andrea Pitts, who engaged with Fanon's work to highlight the structural and interpersonal exhibitions of power within correctional healthcare. Their work was integral to the foundation of this inquiry, and I expand upon their approach by addressing this same relationship outside of the walls of correctional facilities. Focusing on the institution of medicine and the formation of contemporary medical knowledge in the United States, the final section of this paper will clarify the enormous power that medical institutions hold over patients through the provision of everyday clinical care. The covert nature of clinical oppression obscures these conflicts, but this paper will expose them by depicting this relationship in clinical care as a direct parallel to that of correctional healthcare. Mirroring the idea of contrasting loyalty between authority and patient needs, I first discuss bureaucratic interests that have control over the boundaries of care provision-placing my focus on insurance as a network that asymmetrically and amorally restricts care. The existence of dehumanization and reciprocal distrust in the context of clinical care is established by acknowledging the subjective and partisan nature of medical knowledge 
and the tense oppressor-oppressed relationship this fosters. By analogizing the correctional and the clinical contexts, I highlight the control that is present in everyday clinical healthcare and suggest that we question the role of medical institutions in order to recognize them as a part of the imposition of power, rather than objective and infallible entities.

\section{THEORETICAL BACKGROUND}

\section{Frantz Fanon}

A thorough incorporation of Fanon's theoretical work naturally requires a more complete picture of the context in which he engaged. Born and raised in the French colony of Martinique, Fanon's initial observations on being a Black man living under colonial rule came from a place of personal experience - a trend that continued in his work as he invariably rooted his political and philosophical critiques of colonial domination in the lived experiences of the colonized. Fanon's

phenomenological approach is one of his greatest strengths as it grounds his political theory in examples that highlight both the internal and the relational complexities of the French colonial situation in Martinique and Algeria (Pitts 2018). Because of his later involvement in fighting for Algerian independence from France and his advocacy that violent colonization and control should be met with violent revolt, his work is primarily utilized by scholars of political science and post-colonial theory. It is also essential to understand Fanon's own liminal position in Algeria as a Black man in a position of colonial power as a highly educated psychiatrist among predominantly French doctors. Scholar Richard Keller argues that an interpretation of Fanon is incomplete and insufficient if it positions his work as a psychiatrist as a secondary feature of his legacy rather than the "linchpin of his career," because it was in the clinical setting that Fanon was able to observe colonial relationships 
between Algerian patients and French doctors-strengthening his assessment of the power imbalances inherent in relationships with colonial authority (2007:826).

In "Medicine and Colonialism," Fanon documents the distrust that colonized people of Algeria had for all the representatives of colonial authority, clarifying that healthcare is necessarily and inextricably linked to the other systems of control within a colonial context. Asserting that every position of colonial power (e.g., doctor, policeman, schoolteacher) blurs together for the colonized in an "almost organic confusion," Fanon indicates that when Algerians are forced (physically and emotionally) into situations outside of their control, they consider any piece of that coercive force to be working against them (1965:121). Ultimately it does not matter what the specific vocation nor impact of each of these roles is, for these positions are held by French people who hold positions of power that have been imposed involuntarily on Algerian communities. Visits from doctors were "preceded by the assembling of the population through the agency of the police authorities," which therefore renders any physical benefit of the medicine secondary to the traumatic and coercive devices utilized to force this alleged care onto the colonized (Fanon 1965:121). Though there are numerous examples of care being mandated in this way in the ordinary clinical treatment of Algerian patients, the interactions that Fanon documents in A Dying Colonialism are the most directly and unmistakably repressive examples of the collaboration between healthcare and policing because they specifically address control amidst the Algerian war for liberation. Doctors were legally obligated to give the police the name and address of Algerian patients who came in with a wound that appeared as though it could have occurred while they were fighting the occupying armed forces of the French. This direct state repression served its purpose in that Algerian revolutionaries stopped seeking treatment from the colonizing doctors and began providing the necessary first aid work on themselves, which was met with French orders that pharmacists could not sell tools such as alcohol, cotton, antibiotics, or antitetanus serum. Though these examples are extreme due to their context within a war for liberation, 
they confirmed for the Algerian people that "the colonizers were in complete agreement to fight against them" (Fanon 1965:136). The ability of the French authorities to dictate what the doctors legally must do demonstrates the enormous power of the dominant class to shape the rules of medical treatment in a way that benefits them and completely disregards the medical needs of those for whom they allegedly provide care.

Recounting the history of the French occupying presence in Algeria, Fanon elucidates that this reciprocal distrust and the desire to control the bodies of the colonized is not unique to the context of revolution. The colonized Algerian often held a deep distrust for the French doctor, in direct contrast with how Fanon insisted medicine could and should be. Fanon acknowledges that "in a noncolonial society, the attitude of the sick man in the presence of a medical practitioner is one of confidence. The patient trusts the doctor; he puts himself in his hands. He yields his body to him" (1965:123). This concept of consent and yielding your body by conscious choice to someone who has your best interest in mind is something that noticeably does not and cannot exist in a colonial context. The nature of colonialism makes it so that this trust is impossible because the colonial doctor has the interests of the colonizing majority in mind over and above the needs of the Algerian patient. Algerian patients recognized this and "refused to send him to the hospital of the whites, of strangers, of the conqueror," often until it was already too late for any medical care to heal them; this fundamental wariness "is always more or less related to that lingering doubt as to the colonial doctor's essential humanity" (Fanon 1965:125, 124). In the case that colonized patients did seek medical treatment from French hospitals, they were often diffident and yielded neither their bodies nor their thoughts/opinions to the doctor because there was both a lack of trust and a desire to make the process as quick as possible.

An unwillingness on behalf of the patient to yield their pain and their concerns to the white doctor was interpreted as an inability to understand their own health, contributing to Western doctors' 
belief that they were inherently more knowledgeable than the colonized people they treated. The idea of these white, Western 'professionals' as being "superior knowers" on which the colonized people depended not only directly influenced the way medical care was imposed on them, but also upheld the idea that colonized societies would have been worse off without the colonial presence (Pitts 2015:285). Reasonable diffidence on the side of the patient was read as stupidity, unwillingness, and petulance-contributing to the reciprocal distrust between the doctor and the patient. Fanon documents how "the doctor rather quickly gave up the hope of obtaining information from the colonized patient and fell back on the clinical examination ... with these people you couldn't practice medicine, you had to be a veterinarian" $(1965: 126,127)$. Not only was this a flawed medical approach, as it is an incomplete analysis of medical needs, but the colonized body also often physically resisted the doctor as much as they did mentally (Pitts 2015:282). By believing their feelings inferior and their bodies rigid things to be studied independently of the patient's whole person, the colonial doctor established the Algerian as other-the interaction was no longer doctor-patient but instead became subject-object.

\section{Internal Colonialism}

Fanon's $A$ Dying Colonialism was intended to show that "colonialism has definitely lost out in Algeria, while the Algerians, come what may, have definitely won," even though the Algerian War of liberation was not yet over (1965:31). There are many ways to defeat colonialism. To fight, to be in solidarity with your people, to stand in the face of the colonizer's systems and say that you do not need them—-this was Fanon's position when he suggested that Algerians were already victorious. That victory over oppression can take many forms is an insightful stance, scholars have likewise argued that oppression itself is not uniform; "there is no 'post' in colonialism" because the cessation of direct colonial control does not necessarily mean the end of oppression (Allen 2005:10). Internal 
colonialism, alternatively referred to as internal neocolonialism or domestic colonialism, is a theory that posits that colonial power relationships exist "not only international[ly] but intranational[ly]" (González Casanova 1965:27). This paper seeks to use this theory to conceptualize the structural and systemic subjugation Black people experience within the contemporary United States by clarifying that their situation is that of a domestic colony and elaborating the way this colonial power relationship specifically affects the institution of healthcare.

Allen's (2005) commentary on the aftermath of colonialism refers to countries that were once externally colonized and the dynamics that take shape after they have successfully (at least nominally) gained independence; the same case can be made for Black Americans because their situation of oppression has become less overt over time since the United States' history of horrific enslavement, exploitation, and subhuman treatment. That Black-white relationships in the United States began with control and forced dependency_albeit in a slightly different form than traditional external colonialism — set up the same pattern that then shifted into a sneakier version that has been termed internal colonialism.

The theory of the internal colony suggests that racial minorities are subjected to the same exploitative systems that European powers impose on their external colonies. Rather than the colonizing force enacting this absolute power on extraneous countries, it instead exists within the country of the colonial power. Despite the difference in the locality of control, the same colonial relationship can be seen, and the process of colonization is enacted and upheld in the same way. The internal colony thesis is not monolithic in its application, with the discourse community being somewhat divided on what counts as an internal colony. Some scholars have argued that internal colonies must be geographically bounded regions, like Kenneth Clark's famed assessment of ghettos as "social, political, educational, and-above-all-economic colonies" (1965:11). This approach is valuable because 
considering neatly bounded regions as colonies would have a great political advantage in terms of advocating for their liberation and autonomy (Pinderhughes 2010).

Utilized differently within different areas of scholarship, the internal colonialism theory often simply comments on class stratification and primarily economic inequality_but I will be using the lens employed by ethnic studies to highlight the colonial process that shapes the subjugation of minority groups. For the purposes of the present argument, my interpretation of this theory will be aligned with the work of Robert L. Allen, W.E.B. Du Bois, Harold Cruse, and numerous Black political revolutionaries like Malcolm X and Stokely Carmichael, who considered Black people, as a single diasporic colony, to be "a nation within a nation" (Cruse as cited in Allen 2005:2).

In the 1960s, internal colonialism was an important theory within activist circles-heavily used by revolutionary nationalists to advocate for Black liberation (Allen 2005). The idea of liberation itself stems from the understanding of Black people as a colonized people who are actively oppressed by the systems that forcibly govern them. Using language like this makes clear the connection between this colonial situation and that of classical external colonialism; considering that Fanon's $A$ Dying Colonialism was written during the Algerian struggle for liberation, the mirrored patterns of a materially and socially oppressed people fighting to break these chains become apparent. The calls for Black Power and a desire for liberation never resulted in war as it did in Algeria. These revolutionary ideas in the United States were tamped down by the more covert and insidious tactics of neoliberalismand offering minor concessions to quell the more radical voices that were beginning to be heard. The promotion of Black capitalism and the minuscule concession of putting select Black people into middle-class positions of power attempted to conceal the relationship of oppression by nominally lessening the direct subjugation (Allen 2005). These tactics were effective. They quelled some of the less radical voices by making it seem as though victory over oppression could be won through these approved avenues and that there was not a need for liberatory rebellion (Allen 2005). The colonial 
power relationship that shows up in the "territorial concentration, spatial segregation, external administration, the disparity between their legal citizenship and de facto second-class standing, their brutalization by the police, and the toxic effects of racism in their lives" (Gutiérrez 2004:282) did not disappear under this neoliberal veneer of progress: it simply became more covert.

The positionality of Black people as an internal colony in the United States is demonstrably and concretely similar to the colonial situation discussed by Fanon. By using these theories in combination with one another, I will argue that the "coloniality of power" is at work in the contemporary United States and that it permeates every system and institution to structurally disadvantage Black people (Grosfugel as cited in Allen 2005:10). In my utilization of the internal colonialism theory, I am demonstrating that Fanon's observations are applicable outside of their traditional colonial context and are crucial to understanding the colonial relationship that exists within the United States.

\section{CORRECTIONAL HEALTHCARE}

As previously established, one of Fanon's major critiques of healthcare was that it existed in total collaboration with other pieces of the colonial system. Nowhere in the United States is this same pattern more unmistakable than in the correctional system's provision of medical care for those incarcerated. While this section will discuss the power relationships and ethical conflicts that comprise institutional correctional healthcare generally (i.e., within both jails and prisons), my primary focus will be on prisons. As prisons are the most heavily researched and, as the site of more long-term incarceration, prisons provide the most relevant examples of the total control that correctional medical care has over its patients. As a 'total institution' (Goffman 1962), prison ensures that every element of life for those incarcerated is bounded and controlled by the correctional authority. Given that prisoners are stripped of nearly every liberty upon entering the carceral system, 
the 1926 court case Spicer $v$. Williamson elaborated that the burden of medical care fell to the correctional administration, establishing that "the state removes the individual from his usual societal conditions and places him under conditions which deprive him of the ability to help himself. . having assumed this guardianship, the state is under obligation to care for the needs of the individual while he is deprived of the opportunity to care for himself' (Kipnis 2012:377-378). To call again upon the language of the internal colony theoretical framework, prisons exist as an internal colony in the most strict, geographically bounded sense as hegemonized institutions that have perimeters and are removed from a society that benefits from their subjugation. In addition to fitting the geographically-specific definition advanced by Pinderhughes (2010), prisons also still align with Allen's consideration of colonization in the United States as controlling Black people more broadly as Black people and people of color are overrepresented in the prison population; in 2019, there were "1,096 sentenced black prisoners per 100,000 black residents, 525 sentenced Hispanic prisoners per 100,000 Hispanic residents, and 214 sentenced white prisoners per 100,000 white residents in the U.S.” (U.S. Department of Justice 2020).

Though correctional facilities and their governing administrative bodies are responsible for the provision of care, the guidelines on the quality of this care are inconsistent and only loosely obeyed (Sufrin, Kolbi-Molinas, and Roth 2015). Select international organizations attempt to provide comprehensive and detailed boundaries for what can be considered ethical health care in prisons, this includes the "United Nations (UN), the Council of Europe, the World Medical Association, the International Council of Nurses, Physicians for Human Rights, and Penal Reform International" (Pont, Stöver, and Wolff 2012:475). Several of their central and overlapping principles consist of basic ethical considerations such as informed consent and confidentiality. The UN more clearly lays out boundaries of activities that correctional medical personnel in the prisons should not do as they would constitute a breach of medical ethics; largely advocating that medical staff should 
remain committed purely to the health and well-being of their patients and should not take on tasks that the prison wants, such as performing cavity searches, collecting lab samples for drug-detection, and breaking hunger strikes (Pont et al. 2012). Because these regulations are considered "soft law," correctional facilities are not legally obligated to follow them and instead consider them to be loose recommendations (Pont et al. 2012:477). Prisons in the United States legally need only follow national law governing incarceration, of which there are notably few. The 1976 court case Estelle $v$. Gamble is really the only standard for the quality of care that must be provided, this case purely stipulates that "deliberate indifference" to serious medical needs would constitute cruel and unusual punishment which is protected against by the Eighth Amendment (Estelle v. Gamble 1976). The mandate that prisons cannot expressly and deliberately deny medical care serves as the only standard, with no federal legislation regulating the quality nor consistency of care; prisons and jails can be accredited by the National Commission on Correctional Health Care (NCCHC), but it is purely voluntary to participate in their evaluations (Sufrin et al. 2015). Outside of individual court cases seeking to prove deliberate indifference in their or a loved one's treatment in a correctional facility, there is virtually no accountability for prisons that do not provide their inmates with ethical medical care.

Individual-level medical malpractice by prison healthcare providers certainly occurs (Sonenstein 2015b), but the present analysis seeks to highlight more broadly that, at the system level, the driving force behind the provision of correctional healthcare is dependence and control. Some of the most horrific and headline-grabbing atrocities, like the shackling of women in labor (Ahrens 2015) or sending armed guards to the hospital alongside extremely ill patients (Sonenstein 2015a) speak to the fundamental dehumanization of incarcerated people and the need to control them even when they are at their most vulnerable. The often-reluctant provision of medical care is not guided by altruistic concern for those incarcerated, rather it is a burden that must be done so that the 
correctional administration can keep inmates incarcerated and ensure they are capable of doing the labor the facility demands of them.

Prisons take various routes to find medical staff to work at their facilities, one of the popular tactics is to contract a private company whose express purpose is to provide physicians and cover the costs of correctional medical care at a lowered cost to the county that employs them. Sonenstein, in his 2015 three-part exposé "Gaming the System," focused heavily on the company Advanced Correctional Healthcare $(\mathrm{ACH})$ and the decisions they make on what level of care to provide inmates. The ACH very intentionally does not provide the same level of care that the people incarcerated would receive outside of prison—despite organizations like the European Committee for the Prevention of Torture deeming that an essential principle of ethical care. One of the most relevant examples of this being their restrictions on any elective treatments. By barring treatment of any condition that is not directly life-threatening, they are needlessly preventing people from achieving a certain freedom of health care that they may otherwise have. Some examples that scholars have posed are things like gang-related tattoo removal, abortions, even the treatment of acne, that would improve the quality of life of inmates who already have so few liberties afforded to them (Kipnis 2012; Sonenstein 2015a). The ACH also strictly limits over-prescription of drugs, arguing that many of the medicines that doctors would normally give out are actually not necessary within prisons and that they should avoid prescribing them wherever possible, even if it would directly benefit the patient. Ultimately these examples prove the unnecessary and needlessly cruel boundaries of correctional medicine. The goal of prisons is not to provide care, it is to maintain the dependent relationship through which the prisoner is forced to accept the meager services they provide. Further illustrating that the role of medical providers is more for health emergencies and providing just enough care to allow prisoners to serve their sentence than it is for genuine, compassionate, person-centered health care. 


\section{Dual Loyalty and Correctional Interests}

Health care providers are bound to medical ethics that should ensure the same level of care in all settings, including carceral ones. While providers may believe that they are acting in the patient's best interest, the loyalties of correctional medical providers-consciously or unconsciously — are to the governing body in power and not to the patients for whom they allegedly provide care. In his discussion of Fanon and the colonial situation in Algeria, Richard Keller (2007) highlights that "one could serve colonial interests or medical interests, but not both: the adoption of the colonial mantle necessarily meant the abandonment of Hippocratic commitment to patient care" (p. 825). Pont et al. describe this same conflict of interest through what they term 'dual loyalty,' which describes the role conflict between duties to the patient and the "express or implied" interests of a third party such as an employer or the state-which are the same entity in correctional facilities (2012:475). Administrative faculty generally is concerned with security, obedience, and the reduction of expenditures; the presence of these goals within prison administrations shapes their desires for what the provision of medical care looks like under their watch.

This allegiance to the desires of the hegemonic power often manifests through correctional physicians simply obeying the arbitrary rules put in place by the prison administration. By complying with the denial of elective procedures, and by agreeing not to prescribe medicine that may substantially help inmates, they are reinforcing that it is acceptable to deny patients care that is outside of the scope of what the correctional administration thinks they deserve. In agreeing to the punitive goals of the facility they also occasionally avoid practices that would benefit the community health of the entire prison population. When intravenous injections are occurring in prisons despite these actions being prohibited, the most beneficial public health approach would be to introduce harm-reduction practices like needle exchange and distributing information on how to properly clean needles. Because the prison wishes to punish rather than to heal, they do not allow medical 
professionals working in their facilities to condone drug use in this way-even though criminalizing it further does nothing for the safety of those involved (Kipnis 2012). I wish to once again highlight that it does not matter if the healthcare professional feels good about this and wholeheartedly goes along with it. Even when correctional healthcare providers recognize the dissonance between the administration's goals and the prisoners' needs, as employees of the prison, these physicians exist in collaboration with the state to uphold the carceral goals of punishment and control.

\section{Distrust and Dehumanization}

As such, prisoners are often under no illusion that the medical providers are acting in their best interest. A large part of this stems from the role overlap in which primary care providers for inmates are often utilized to perform surveillance tasks at the behest of their superiors-entirely ignoring the aforementioned UN recommendation that their focus should be solely on patient care. Pont et al. (2012) clarify:

the switch from a professional's position of personal confidential caregiver with undivided commitment to the prisoner patient to acting as a forensic or public health officer accountable to the authorities—whose report might harm the patient—certainly is detrimental to the patient's trust, even if thoroughly explained. (p. 476)

How are patients expected to trust that the caregiver is working for them and their needs when they are simultaneously taking samples for drug tests and doing cavity searches? These acts are clearly ones where the provider reports the findings to the wardens and correctional officers, how is the patient supposed to trust the confidentiality of their wellness visits? The distrust that the colonized patient expresses towards the colonizer's doctors are thus very similar to what occurs in prisons because the understanding is the same: they do not work for the patients, they work for the dominating power. 
The correctional medical situation mirrors the colonial medical situation in that the distrust is both pervasive and reciprocal. Just as colonial doctors did not trust the reporting of the colonized patient, incarcerated people's conception as inherently untrustworthy leads to an overreliance on the opinion of the doctor over and above that of the patient. Andrea Pitt's 2015 piece echoes this sentiment by establishing that medical and correctional staff "may deem themselves superior knowers" because they do not believe that prisoners have the language or knowledge to discuss what they are feeling and accurately request what they need (p. 285). I believe it is helpful in this segment to continuously provide the support of specific instances and case studies to move these abuses of power from the theoretical and highlight the very real impact this has on incarcerated patients. In their extremely relevant piece on correctional healthcare, Pitts brings to light the story of a woman whose concerns surrounding a gynecological procedure and her personal history of abuse were laughed off by the attending correctional care provider. When the patient tried to tell the doctor that she would need to be sedated for the procedure he shifted quickly from laughter, to not believing her, to trying to guilt her out of it by acknowledging how many extra administrative steps he would have to go through. While it is possible to spend pages and pages discussing this horrific dismissal alone, I wish to highlight that ultimately she had her psychiatrist write a note to the doctor explaining the exact same things that she had said in their visit and that was enough to make him believe her and to take the extra steps without further complaint because, as the patient recognizes, “[the psychiatrist's] word carries weight” (Pitts 2018:19). There is something to be said about the fact that the doctor trusted (or at least was administratively forced to trust) the word of a fellow medical staff member, and it is frightening to consider the way the nonconsensual procedure would have gone without another "professional" to back the patient up. The story of this patient is one of many similar stories that also highlight that these incarcerated patients are seen as bodies, they are seen as objects, as pieces of the red tape that are merely an inconvenience for the doctor rather than 
complex human beings with complex physical and emotional needs. Incarcerated patients recognize this detached and disinterested approach of the correctional doctor, it becomes clear that their medical needs are an inconvenience — and why ask for compassionate care when these prisoners know they will not receive it? What the correctional and the colonial doctor may read as diffidence or rigidity is the understanding that the doctor would not believe them even if they tried to convey their needs.

It warrants discussion that prisoners make up a specific subset of the population that is perceived as untrustworthy and manipulative by virtue of them having been incarcerated. The presumed possibility that these patients may be lying, especially in pursuit of drugs, leads to an increased dismissal of their needs. Since this stigma automatically treats patient reporting as unworthy of serious consideration, the correctional physician will routinely rely solely on physical examination. The whole picture of health concerns is often not visibly apparent, and assuming that a patient is misrepresenting their pain can cause the physician to neglect very serious ailments (Sonenstein 2015b).

Prisons serve as geographically bounded colonies holding some of the most marginalized people in the United States; the overt, coordinated control of the administrative bodies governing these facilities enacts the colonial relationship of domination and subjugation within their walls. The enclosed nature of prisons provides the clearest example of an internal colony and the colonial dynamics of oppression because it is easiest to assert control within total institutions. The common assumption, however, is that there is a fundamental difference between "the brutality of prison life and the allegedly autonomous norms" of healthcare that is provided to people outside of correctional institutions (Ahrens 2015:1). The present argument seeks to clarify that the repressive relationship in medicine exists outside of these walls as well through the same patterns of dogmatic power and the intersubjective distrust this sows. 


\section{CLINICAL HEALTHCARE}

It is one thing to discuss the ethical conflict and dehumanization that occurs in correctional settings: at some level, that feels fathomable because interrogations into prison abuses are increasingly bringing this into the collective consciousness. It is more complicated to expose the flaws within the institution of clinical healthcare in the United States as its injustices are often concealed by its potential benefits. Highlighting the structural and deeply embedded flaws in institutions that provide necessary services, such as healthcare, is a task that is both essential and formidable. I wish to clarify this position by acknowledging that Fanon was a vocal supporter of medicine itself-he believed that the tools, methods, and scientific practices that the French brought to Algeria were an objective good, but that the amoral application and the systemic othering that governed the creation and dispersion of this care gave it its oppressive structure (1965). It is essential to understand that medical advancements in the United States, both presently and historically, are inseparable from the politics that determine who controls them. I established earlier that internal colonialism functions to make the systemic subjugation of Black people more covert than it was in the days of enslavement, segregation, and restricted civil rights. In the same way, the convoluted and dehumanizing medical care that disproportionately harms Black Americans in contemporary clinical settings is no less unethical than that which takes place in prisons: it merely manifests in subtler ways.

\section{Dual Loyalty and Bureaucratic Boundaries}

This section intends to highlight the flaws in the structure of healthcare itself, over and above the effects of interpersonal doctor-patient relationships. The complicated and piecemeal network of healthcare in the United States prioritizes profit above medical ethics and relies on labyrinthine systems that force dependency (Supri and Malone 2011). Medicine currently operates in the United States as a network that is vast and decentralized in a way that is obscure and difficult to navigate; 
more specifically it is "comprised of a myriad of large and powerful organizations, including insurance companies, Health Maintenance Organizations (HMOs), corporate for-profit hospital chains, and pharmaceutical companies" that must communicate among themselves and with the patient in order to achieve care that is even somewhat comprehensive (Supri and Malone 2011:192). Not only does this make it difficult to maintain continuity of care (i.e., providers that are consistently involved in all that is going on with your health), but this disjointed assemblage of for-profit organizations is also logistically and financially daunting to navigate. Considering healthcare as a system rather than focusing on individual actors highlights the impact of "institutions, markets, and health care delivery systems" that govern the business of healthcare (Metzl and Roberts 2014:675); this section will elaborate the way that the business of healthcare leads to decreased commitment to altruistic medical ethics and maintains healthcare as an exclusive service.

The previous section established Pont et al.'s concept of dual loyalty through correctional medical providers' commitment to serving the needs of the prison above the needs of their patients. The full definition provided in Pont et al.'s 2012 piece defines dual loyalty as "clinical role conflict between professional duties to a patient and obligations, express or implied, to the interests of a third party such as an employer, an insurer, or the state" (475, emphasis added). Carceral caregivers' loyalty to the correctional administration demonstrated allegiance to an entity that is both the employer and the state. This section will illuminate that loyalty to the insurer-and the mere existence of an insurer as a mediating factor-in clinical healthcare settings likewise leads to inadequate and inequitable patient care. Edmund Pellegrino discusses this conflict in his ruminations on systems of managed care and how they force physicians to contain medical costs, stating succinctly that "any system of managed care, by its nature, places the good of the patient into conflict with ... (1) the good of all the other patients served by the plan; [and] (2) the good of the plan and the organization, themselves, as expressed in the limits they place on care" (1994:506). Because of the way the institution of medicine- 
more specifically, its funding - is set up, care providers are beholden to convoluted and rigid systems of insurance whose main goal is profit and the reduction of expenditures. Using bureaucratic terminology is insidious when the expenditures it refers to are services that directly affect patients' lives.

Insurance establishes a system of forced reliance by mediating healthcare in such a way that people cannot opt out - by privileging those who have the financial and cultural capital to navigate it, this system makes care disproportionately inaccessible for Black Americans. Historically, "working for an employer who provided health insurance was the most realistic route to coverage for the uninsured" (Flores and Vargas 2017:2057). While other options are gradually becoming available for attaining at least some level of insurance coverage, such as state coverage and increasing expansions to Medicaid, job-provided insurance plans remain one of the major options for comprehensive coverage. This means that disproportionately high rates of unemployment among Black Americans compound inequality through the disparate provision of health insurance (Flores and Vargas 2017). Bonnie Bullough's research on how poverty and race affect access to, and usage of, preventative healthcare further demonstrates that though there are alternative routes to insurance (e.g., Head Start, state programs, and Medicaid), their unique and rigid criteria for eligibility "results in spotty coverage and means that free care is not necessarily available for every mother and child who needs it" (1972:351). The existence of alternative routes to coverage does not guarantee accessibility, nor are these alternatives direct substitutes for employer-provided plans. With a lack of truly universal access to care, these less comprehensive programs are often the only choice-forcing already subordinated populations to accept any plan that provides them some healthcare because their only other option would be to have none. The intentionally confusing and fragmentary configuration of insurance markets adversely affects those who have not been trained or do not have the time to navigate it-inequitably affecting non-white, working-class Americans (Supri and Malone 2011). 
By complying with the boundaries dictated by insurance companies and fee-for-service care, medical professionals uphold the profit-driven structure of U.S. healthcare. Medical care is inextricably tied to the political institutions that govern it and control who has access to it. The refusal of the United States government to provide access to free, universal healthcare is in itself a tactic that systemically oppresses people of color; the obedience of medical providers to the current unethical structure illustrates that their loyalty will always be to each other, rather than to the people for whom they allegedly provide care. Actively upholding boundaries that are antithetical to patient needs is not a neutral act. Just as Fanon was adamant that colonial doctors could not be simultaneously loyal to the patients and to the colonial mantle (1965:852), obeying the boundaries of care that are dictated by the bureaucracy of healthcare—at both the organizational and governmental level—means that the loyalty will never solely be to the patient.

\section{Distrust and Dehumanization}

The deep distrust of physicians that was held by colonized Algerians and is currently held by those incarcerated in U.S. prisons stems from the understanding that even the most compassionate caregiver among them operates within institutions that treat them as objects to be controlled. The present argument would be remiss if it did not acknowledge the endemic medical mistreatment and abuse that has targeted Black people throughout the history of the United States. Slavery as an economic system established Black people as tools to be used for their labor, the accompanying racist ideology considered Black people to be subhuman and used this to justify treating them as objects in every context. The medical profession in the antebellum period attempted to advance medical knowledge through the "use of slaves and free Black people as subjects for dissection and medical experimentation" (Gamble 1997:1774). Painful, nonconsensual procedures done without anesthesia were commonplace, and even the bodies of deceased Black people were frequently exhumed to be 
used to satisfy the whims of the white doctor (Gamble 1997). The abolition of slavery and the provision of legal civil rights ultimately established that medical ethics must also apply to Black Americans, which helped to reduce some of the most overt medical exploitation. This mistreatment certainly did not disappear, however; it just became less consistently documented. Black folklore following the Civil War provides some of the clearest recounting of how the threat-both real and perceived—of medical abuse continued to haunt them (Gamble 1997). This limited summary of some of the earliest abuses is intended to demonstrate that U.S. medical care originated with the complete disregard for the humanity and personhood of Black people and the abuse of their bodies and souls to benefit the medical care of white people.

Despite eventually attaining nominally the same medical rights as white people, ethical standards have historically been inconsistently applied-to the detriment of Black people's health, safety, and faith in medical institutions. One of the most well-known examples of this flagrant harm is the Tuskegee Syphilis Study: where Black male participants were misled, lied to about their own health, and "deliberately denied effective treatment for syphilis in order to document the natural history of the disease" (Gamble 1997:1773). This study ran from 1932 to 1972 and displays the same conscious disregard for the health of Black people and the prioritization of their bodies as experimentation sites as had been seen in the centuries prior. In 1997, twenty-five years after the atrocious details of the Tuskegee study came to light, President Clinton issued a formal apology for the experiment and acknowledged the distrust of the healthcare system that it had caused; it remains arguably the salient example, one that "has come to symbolize racism in medicine, misconduct in human research, the arrogance of physicians, and government abuse of Black people” (Gamble 1997: 1773). While it is impossible to convey the depth and pervasiveness of these atrocities with due rigor within the scope of this paper, it is essential to acknowledge the historical and ancestral trauma that exists for Black Americans seeking healthcare today and to understand that contemporary care as it 
exists today cannot be separated from its past abuse. This is the foundation of clinical healthcare in the United States: it has never been moral, it has never been impartial, and it has never been separate from its social and political context.

Anti-Black abuse within medicine is often understood to be a piece of the history of healthcare, but the exploitation and manipulation of Black bodies was one of the primary tools used by white doctors in their attempts to advance medical knowledge. Misrepresenting racism in medical care as merely a peripheral occurrence obscures the extant impact of racialized knowledge. Metzl and Roberts (2014) further elucidate this via three case studies that illustrate the complex interrelationship between “extraclinical stigma, socioeconomic factors, and politics," and trends of diagnosis and treatment (p. 675). In the 1960 s and 1970 s, Black men were diagnosed with schizophrenia "65 percent more frequently" than white men (Metzl and Roberts 2014:675). The initial assumption was that miscommunication and mistrust during the clinical encounter had caused this disparity, but education initiatives to counter clinician bias did not have any effect on the trend. Further analysis revealed that this overdiagnosis occurred in large part because the second edition of the Diagnostic and Statistical Manual (DSM) changed the description of schizophrenia to "a condition of 'hostility,' 'aggression,' and projected anger" (Metzl and Roberts 2014:676). Defining schizophrenia in this way led not only to overdiagnosis, but to over-prescription of drugs like Haldol that promised "cooperation" from the Black men that were "assaultive and belligerent" (Metzl and Roberts 2014: 677). Prior to this new definition, however, schizophrenia was considered a mental illness of secluded, sensitive housewives - illustrating the way clinical diagnosis and its prescribed treatment are not impartial nor constant. Metzl and Roberts clarify that this historical example "resulted neither primarily from individual doctors' biases nor from the actions or symptoms of patients... rather, it reflected a series of structural shifts in the framing of mental illness that incorporated racially and politically inflected terminology" (2014:678). Ascribing these terms to their Black patients, then, was not an example of 
individual bias but rather medical professionals obeying and upholding the bias that was embedded in the diagnostic structure. This case is just one example of racialized language and stereotypes being embedded in medicine's very tools, the symptoms it looks for, and the treatment it prescribes. Medical diagnostic tools and treatment methods are formed, created, and discovered within a specific racial, social, and political context-their socially constructed nature means they are neither neutral nor impartially applied.

Despite the highly subjective nature of medical knowledge, clinical healthcare often assumes that reliance on scientific "objectivity" is a viable method of achieving ethical healthcare. The dominant diagnostic model of modern clinical care has been the bio-medical approach, "in which doctors isolate patients from their psycho-social world and reduce them into a diseased organ or an impaired gene" (Coşkun 2015:33). Relying primarily on the body to encapsulate and accurately relay the whole story of a patient's health stems from the belief that the body contains all the necessary evidence, and the clinician must assume the role of detective. Under this approach, the provider uses an "objectifying touch" in pursuit of what they consider "more objective and therefore more reliable data than subjective patient accounts of symptoms" (Leder in Pitts 2018:23). As medical technology has become more widely available and more heavily utilized, diagnostic techniques have retained this same character but have led to a more "absent touch" as professionals rely on scans and laboratory results to relay data regarding patient needs (Leder in Pitts 2018:23).

This approach presumes that reading the body on its own makes it easier to separate physical needs from social attributes of the patient that may prompt biased treatment-such as race or socioeconomic status. Placing this in conversation with the earlier discussion of the colonial clinical relationship, Fanon highlighted that the colonial doctor likewise "fell back on the clinical examination" and acted as a "veterinarian" to the colonized patient $(1965: 126,127)$. The colonial doctor's belief that the Algerian patients did not understand their own health or needs was justification for the doctor to 
treat them as objects: reinforcing the power dynamics that prevented truly person-centered medical care. In the contemporary United States, as in the colonial context, approaching the patient as a body rather than a person strips them of their positionality and ignores the myriad complex social factors that are integral to a complete understanding of their health. Rather than ignoring critical facets that affect patient health, Dr. Camara Phyllis Jones advocates an even more comprehensive consideration of these elements. Jones asserts that it is not enough to consider race as a characteristic, or as a demographic box to be checked; she posits that race is only valuable if it is understood as something that actively affects the health of patients through racism at the personal, interpersonal, and institutional level (2002). Metzl and Roberts likewise advocate a move towards 'structural competency' which acknowledges the broader structural contexts that impact patient health, such as "health care and food delivery systems, zoning laws, local politics, urban and rural infrastructures, structural racisms, or even the very definitions of illness and health" (2014:674). Combatting dehumanization and objectification in healthcare cannot be achieved through further depersonalization. Allowing healthcare to systematically separate body from person in an attempt to achieve some ideal of impartiality that has never existed in medicine will only uphold the oppressive structure of its application.

\section{CONCLUSION}

In this paper, I have proposed the use of Frantz Fanon's theoretical work to engage with the function of the institution of medicine in the United States. Colonial contexts, in general, provide an understanding of dominance that demonstrates the enormous power of the governing body to define and constrain every aspect of the lives of those under their control. Considering medical institutions as an arm of the dominant authority allows for greater scrutiny regarding their principles, the boundaries that are placed on care, and who those boundaries affect. 
Through an analysis of both correctional and clinical healthcare, this inquiry has clarified that medical oppression does not simply exist on its own; medicine as an institution actively and systemically oppresses people. Created, defined, and applied by the dominant authority, medical knowledge and medical care are neither objective nor neutral. I have argued that it is essential to ground medical institutions in their specific sociopolitical context because treating them as infallible and unchangeable upholds the myth that their care is impartial. Questioning how the boundaries of care affect people and assessing whether these effects are equitable is critical to achieving truly just healthcare.

Given the difficulty of noticing and appraising these same dynamics in the country and in the sociopolitical context with which one is familiar, I advocate for the use of Fanon and scholars like him in order to call attention to oppression in noncolonial contexts. It is only through elucidating asymmetrical and coercive power dynamics that we can set about dismantling these unjust systems and begin truly providing what medicine intends to: care for all who need it. 


\section{REFERENCES}

Ahrens, Deborah. 2015. “Incarcerated Childbirth and Broader 'Birth Control': Autonomy, Regulation, and the State." Missouri Law Review 80(1):1-32.

Allen, Robert L. 2005. "Reassessing the Internal (Neo) Colonialism Theory." The Black Scholar 35(1):2-11. doi: 10.1080/00064246.2005.11413289.

Bullough, Bonnie. 1972. "Poverty, Ethnic Identity and Preventive Health Care." Journal of Health and Social Behavior 13(4):347-59. doi: 10.2307/2136826.

Clark, Kenneth Bancroft. 1965. Dark Ghetto: Dilemmas of Social Power. [1st ed.]. New York: Harper \& Row.

Coşkun, Ahmet. 2015. "Dehumanization as an Ethical Issue in the Health Services Sector." Turkish Journal of Business Ethics 7(2):9-51. doi: 10.12711/tjbe.2014.7.2.0160.

Estelle v. Gamble, 429 U.S. 97 (1976).

Fanon, Frantz. 1965. "Medicine and Colonialism.” P. 181 in A Dying Colonialism. New York, Monthly Review Press.

Flores, René D., and Robert Vargas. 2017. "Medicaid Expansion and Ethnoracial Disparities in Health Insurance Coverage." Journal of Ethnic and Migration Studies 43(12):2055-71. doi: 10.1080/1369183X.2017.1323451.

Gamble, Vanessa Northington. 1997. "Under the Shadow of Tuskegee: African Americans and Health Care." 87(11):28.

Goffman, Erving. 1962. Asylums. Aldine Publishing Company. 
Gonzalez Casanova, Pablo. 1965. "Internal Colonialism and National Development.” Studies in Comparative International Development 1(4):27-37. doi: 10.1007/bf02800542.

Gutiérrez, Ramón A. 2004. “INTERNAL COLONIALISM: An American Theory of Race.” Du Bois Review: Social Science Research on Race 1(2):281-95. doi: 10.1017/S1742058X04042043.

Jones, Camara Phyllis. 2002. “Confronting Institutionalized Racism.” Phylon (1960-) 50(1/2):7-22. doi: $\underline{10.2307 / 4149999}$.

Keller, Richard. 2007. "Clinician and Revolutionary: Frantz Fanon, Biography, and the History of Colonial Medicine." Bulletin of the History of Medicine 81(4):823-41.

Kipnis, Kenneth. 2012. "Social Justice and Correctional Health Services.” Pp. 373-84 in Medicine and Social Justice: Essays on the Distribution of Health Care: Essays on the Distribution of Health Care, edited by R. Rhodes, M. Battin, and A. Silvers. Cary, UNITED STATES: Oxford University Press, Incorporated.

Metzl, Jonathan M., and Dorothy E. Roberts. 2014. "Structural Competency Meets Structural Racism: Race, Politics, and the Structure of Medical Knowledge." AMA Journal of Ethics 16(9):674-90. doi: 10.1001/virtualmentor.2014.16.9.spec1-1409.

Pellegrino, Edmund D. 1994. “Words Can Hurt You: Some Reflections On The Metaphors Of Managed Care." The Journal of the American Board of Family Practice 7(6):505-10. doi: $\underline{10.3122 / \mathrm{jabfm} .}$

Pinderhughes, Charles. 2010. "How Black Awakening in Capitalist America Laid the Foundation for a New Internal Colonialism Theory." The Black Scholar 40(2):71-78. doi: $\underline{10.1080 / 00064246.2010 .11728716 .}$ 
Pitts, Andrea J. 2014. 'White Supremacy, Mass Incarceration, and Clinical Medicine: A Critical Analysis of U.S. Correctional Healthcare.” Radical Philosopby Review 18(2):267-85. doi: $10.5840 /$ radphilrev201412827.

Pitts, Andrea J. 2018. "Examining Carceral Medicine through Critical Phenomenology.” International Journal of Feminist Approaches to Bioethics 11(2):14-35. doi: 10.3138/ijfab.2017.08.11.

Pont, Jörg, Heino Stöver, and Hans Wolff. 2012. "Dual Loyalty in Prison Health Care.” American Journal of Public Health 102(3):475-80. doi: 10.2105/AJPH.2011.300374.

Sonenstein, Brian. 2015a. "Advanced Correctional Healthcare Doctor Faces Multiple Federal Lawsuits." Shadowproof. Retrieved March 10, 2021 (https://shadowproof.com/2015/08/10/advanced-correctional-healthcare-doctor-facesmultiple-federal-lawsuits/).

Sonenstein, Brian. 2015b. “Advanced Correctional Healthcare’s Brutal Brand of Jailhouse Medicine.”Shadowproof. Retrieved March 10, 2021 (https://shadowproof.com/2015/08/03/advanced-correctional-healthcares-brutal-brand-ofjailhouse-medicine/).

Sufrin, Carolyn, Alexa Kolbi-Molinas, and Rachel Roth. 2015. "Reproductive Justice, Health Disparities And Incarcerated Women in the United States." Perspectives on Sexual and Reproductive Health 47(4):213-19. doi: 10.1363/47e3115.

Supri, Salinder, and Karen Malone. 2011. “On the Critical List: The US Institution of Medicine.” The American Journal of Medicine 124(3):192-93. doi: 10.1016/j.amjmed.2010.11.010. 
U.S. Department of Justice. 2020. Prisoners in 2019 - Summary. Statistical Report. NCJ 255115. Bureau of Justice Statistics. 